\title{
Process evaluation of the implementation of a parenting programme for Somali-born parents living in Sweden
}

\author{
Fatumo Osman ( $\nabla$ fos@du.se ) \\ https://orcid.org/0000-0002-0038-9402 \\ Ulla-Karin Schön \\ Stockholms Universitet \\ Marie Klingberg-Allvin \\ Hogskolan Dalarna \\ Renée Flacking \\ Landstinget Dalarna \\ Malin Tistad \\ Hogskolan Dalarna
}

\section{Research article}

Keywords: culturally sensitive, immigrant, implementation, parenting programmes, parental support, reach, recruitment

Posted Date: July 17th, 2020

DOI: https://doi.org/10.21203/rs.3.rs-20706/v2

License: (a) (i) This work is licensed under a Creative Commons Attribution 4.0 International License. Read Full License 


\section{Abstract}

Background: Forced migration has been shown to have a negative impact on family dynamics, parenting and the parent-child relationship. Parental support programmes aim to strengthen family functioning and the parent-child relationship and to promote the mental health of children and parents. However, there is a lack of knowledge on how parenting support programmes can be implemented for newly arrived immigrant parents. This process evaluation, therefore, describes the implementation of a successful parenting programme for immigrant parents from Somalia and identifies key components in the implementation process.

Method: This process evaluation considered context, implementation and mechanism of impact, in accordance with the Medical Research Councils guidance. Data were collected through focus group discussions, a questionnaire, attendance lists, field and reflection notes, and observations of the sessions. The data were then analysed using content analysis and descriptive statistics.

Results: The findings showed that of the 60 parents who were invited to the parenting programme, 58 participated in the sessions. The study showed that involving key individuals in the early stage of the implementation facilitated reaching the Somali-born parents in the parenting programme. To retain the participants in the programme, parents were offered free transportation. The programme was implemented and delivered as intended. A majority of the parents were satisfied with the programme, and they reported increased knowledge about children's rights and the support they might seek from social services.

Conclusions: This study illustrates how a parenting support programme can be implemented for Somali-born parents and provides guidance on how to engage and attract immigrant parents to participate in parenting support programmes.

\section{Introduction}

Over the past decade, several countries in Europe have received a large number of refugees who have fled from war, fear of persecution and environmental disaster [1]. Forced migration has a strong effect on the health of the individual [2], families' transition to the host country (i.e. acculturation) [3, 4] and parent-child relationships [5-7]. Several studies have addressed the challenges that immigrant parents encounter in the new home country on different levels $[8,9]$. Challenges on the family level include the lack of extended family, the change in roles and the power conflicts between parents and children due to their different levels of acculturation [7, 10]. Challenges on a societal level include a lack of understanding in terms of the parenting system in the new home country, fear that authorities will remove the children from their families and sense of discrimination by social services $[6,11,12]$. The parents' fear of social services and sense of discrimination may hinder them from seeking support for their parenting $[6,11,12,13]$. This forced migration and the acculturation process are challenges that may impact family dynamics, parenting and the parent-child relationship [8-10].

However, migration has also been described by immigrant parents as an opportunity to rethink and modify their parenting [13]. Immigrant parents have stressed a need for extensive support in improving and adapting their parenting role and skills in the new home country, as well as strengthening parent-child relationships $[10,13$, 14]. Parenting programmes have been found to strengthen the functioning of families and parent-child relationships, and to promote the mental health of children and parents $[15,16]$. Despite these benefits, studies 
have revealed numerous challenges when it comes to engaging, recruiting and retaining immigrant parents in parenting programmes $[17,18,19]$. Several studies have highlighted the importance of delivering a parenting programme in the participants' native language by people with cultural and contextual competences $[5,7,13$, 14] and that a lack of cultural sensitivity in such programmes contributes to low participation and high dropout rates among immigrant parents $[18,20]$. Most other types of parenting programmes also lack cultural sensitivity, and all are delivered in the language of the host country [18].

Implementation, the process of putting a programme to use [21], involves dimensions such as fidelity, adaptation and reach [22]. Evaluation of programme fidelity is generally defined as the degree to which a programme is delivered as intended [23], and knowledge about programme fidelity is crucial if conclusions are to be drawn about the outcome of a programme. Whereas the importance of programme fidelity is widely accepted, less focus has been given to the need for clarity with regard to implementation strategies that are used to implement a programme and that relate to fidelity to those strategies [24]. A first step is to clearly describe the strategies used to support the implementation [25] in order to enable evaluation of fidelity to these strategies. Reach is defined as the ability of a programme to engage its target audience and is crucial for the programme's potential to impact public health [22]. If the strategies used for implementation of parenting programmes are not properly evaluated and core components of the strategies are not described, the future implementation of such programmes will remain both challenging and hard to achieve.

In previous studies $[15,16]$, we developed and evaluated the effectiveness of a culturally tailored parenting programme [the Ladnaan Programme] to Somali-born parents in Sweden. Our findings showed that the Ladnaan Programme decreased children's behaviour problems [15] and improved parents' mental health and sense of parental competence [16]. Somali-born parents reported that the culturally tailored parenting programme strengthened their parenting and parent-child relationship [26]. Because of the proven benefits of the programme, it is crucial to explore how the implementation of the programme and its reach to the target group were obtained in order to guide future implementation of similar programmes and to provide information to policymakers about the potential of the programme to be employed in other settings.

In conclusion, there is a lack of knowledge about effective implementation strategies used to support the implementations of culturally tailored parental support programmes. Such knowledge is crucial for the implementation of beneficial parenting programmes in ordinary practice that have programme fidelity, and that can reach and retain hard-to-reach groups. The aim of this study was therefore to increase knowledge about effective strategies that can be useful in the implementation of a parenting programme for immigrant parents from Somalia with special focus on how to reach and retain the target group.

\section{Methods}

\section{Design}

The study is a process evaluation, which was a part of a randomised controlled trial in which we evaluated the effectiveness of a culturally tailored parenting programme to Somali-born parents living in Sweden [see more details on other studies, 15, 16]. This study focuses on the process of delivering the Ladnaan Programme with a special focus on reach and programme fidelity. The guidance for process evaluation as suggested by Moore et al. [22] provided a structure for the study. The three components context, implementation and mechanism of 
impact were used to describe the context for the implementation, the way in which the implementation strategy was carried out and potential mechanisms for achieving implementation with programme fidelity and reach [Table 1].

Table 1

Blueprint of key components in the process evaluation

\section{Description of the components Questions in the process evaluation Data sources}

\section{Context}

Contextual factors that affect

the implementation process

and mechanism of change

\section{Implementation process}

How delivery of the implementation is achieved
What were the contextual barriers and facilitators for reaching and retaining the target group?

What were the contextual barriers for participation of the group leaders?

Reach: To what extent did parents in the target group participate in the intervention?

Fidelity: What adaptions of the implementation strategy were made and how was the strategy perceived?

To what extent was the Ladnaan Programme delivered as intended and how did group leaders perceive the delivery?
Focus group discussions [FGDs] with group leaders and internal facilitators Field notes

Attendance list

Field notes

Field notes

FGDs with group leaders

FGDs with internal

facilitators

FGDs with Connect

instructors

Participant observations

during societal information

Reflection notes from

lecturer

FGDs with group leaders

Were group leaders satisfied with the delivery of the intervention?

Were the participants/parents satisfied with the intervention?
FGDs with group leaders

Client satisfaction

instrument to parents

\section{Setting}

The study was conducted in a medium-sized municipality in Sweden with a population of 51000 . Over the past 15 years, the municipality has received a large number of immigrants: by the end of $2017,17 \%$ of the municipal population was foreign-born [27], with Somalis making up one of the largest immigrant groups. The municipality's Social Services had experienced considerable difficulty reaching out to immigrant parents and were therefore determined to find ways to engage hard-to-reach groups in parenting programmes [28].

\section{Intervention}

The Ladnaan Programme had two components: Connect parenting programme [29] and societal information (Fig. 1). Connect is a 10-session parenting programme derived from attachment theory [29]. Its primary aim is to promote children's mental health and strengthen the parent-child attachment relationship [29]. The Connect programme was chosen based on findings from previous research [13] showing that Somali-born parents were expressing a need to strengthen their relationships with their children. 
The societal information component comprised two of the 12 sessions of the Ladnaan Programme and was developed from a previous study on the need among Somali immigrant parents for parenting support [13]. The societal information component of the current programme contained three parts: Child Welfare Services, Parenting Styles and the United Nation's Convention on the Rights of the Child (CRC).

The programme was delivered four times to four separete groups, and each programme had 12 sessions, which was attended by 12-17 participants, and delivered by two group leaders (one female and one male). Each Connect programme session lasted one hour and each societal session lasted 2-3 hours. All group sessions were conducted in Somali except for the single session on Parenting Styles that was delivered by a Swedishspeaking professional from Family and Child Welfare Services and interpreted by one of the group leaders.

The programme was delivered with a culturally sensitive approach, which was developed from the findings of a previous study [13] and involved tailoring the parenting programme to the parents' needs, culture and context. The programme was named Ladnaan (a Somali word referring to a sense of health and wellbeing), and the term parent empowerment was to reflect the fact that the programme was meant to empower the parents rather than control them.

The Ladnaan Programme was delivered in Somali by group leaders who had cultural competence relating to both Swedish and Somali society. After each session, parents received translated and summarised hand-outs about the session. In addition, Somali metaphors and proverbs were used during the sessions to make the content comprehensible and to affirm certain content.

\section{Implementation Strategies}

The implementation strategies focused on the implementation of the Ladnaan Programme; the recruitment and training of the group leaders and lecturers; and the reaching and retaining of parents.

\section{Recruitment and training of group leaders}

The main task for group leaders was to deliver the Connect sessions. Initially, nine group leaders (five males and four females) with a Somali background who were employed at the social services, integration office for newly settled refugees and schools were recruited to ensure that the parenting programme would be sustainable even after the study had concluded (Table 2). The group leaders received 4 days of standardised Connect training provided by Connect instructors who were qualified to train group leaders [30].

Two of the group leaders and one lecturer from municipal Family and Child Welfare Services delivered the societal information sessions.

\section{Strategy to reach and retain the target group}

Strategies to reach and retain parents included the following components: 1 ) informal information meetings [held in small groups and at the individual level]; 2) diploma for parents who participated in the parenting programme; 3 ) times for meetings adapted to the needs of the parents; 4] session venue in the neighbourhood where most families lived; 4) reminders; 5) babysitting services; and 6) assistance reading and answering letters from government agencies. 
Parents first received information about the parenting programme at an informal meeting held in Somali associations and schools, and at the Workers' Educational Association. The meetings were arranged together with the Somali associations and key individuals (Somalis from the municipality who were well respected within the Somali community). Parents who were interested in receiving more information were phoned by the external facilitator (member of the research group), who gave them detailed information about the parenting programme.

The key individuals and the external facilitator suggested an award of a diploma to parents could be a way to facilitate recruitment; as such, parents were informed that they would be given a participation diploma if they completed the parenting programme. The sessions were held late afternoon in a neighbourhood where most of the parents lived at a time and place chosen by the parents.

Text-message reminders were sent to parents by internal facilitators the day before each session. Childcare was offered to parents who required it so as to increase the chances of both parents attending the sessions. Parents were also offered assistance reading and replying to letters from authorities. According to the Somali associations, many parents in the community often sought their assistance to read government letters.

\section{Study Participants}

Involved in the study were group leaders, a lecturer, Connect instructors and internal facilitators who participated in the implementation process (Table 2) as well as parents who participated in the parenting programme. The participants who were involved in the implementation of the programme were eight females and six males. Their roles and characteristics are described in Table 2. 
Table 2

Characteristics of the study participants, their area of responsibility and workplace

\begin{tabular}{|c|c|c|c|}
\hline & $\begin{array}{l}\text { Area of responsibility in the } \\
\text { intervention }\end{array}$ & Workplace & $\begin{array}{l}\text { Educational } \\
\text { background }\end{array}$ \\
\hline \multirow{5}{*}{$\begin{array}{l}\text { Group } \\
\text { leaders* [n } \\
=8]\end{array}$} & \multirow{5}{*}{$\begin{array}{l}\text { - Delivering the Connect } \\
\text { programme } \\
\text { - Help reading and writing letters } \\
\text { from government agencies }\end{array}$} & $\begin{array}{l}\text { Social Services: Department of } \\
\text { Family, Children and Youth }\end{array}$ & $\begin{array}{l}\text { University } \\
\text { degree }[\mathrm{n}=1]\end{array}$ \\
\hline & & $\begin{array}{l}\text { Social Services: Department of } \\
\text { Employment and Integration }\end{array}$ & $\begin{array}{l}\text { Upper } \\
\text { secondary } \\
\text { diploma }[n=1]\end{array}$ \\
\hline & & Integration office & $\begin{array}{l}\text { University } \\
\text { degree }[n=1] \\
\text { Upper } \\
\text { secondary } \\
\text { diploma }[n=1]\end{array}$ \\
\hline & & $\begin{array}{l}\text { Schools: primary and secondary } \\
\text { school }\end{array}$ & $\begin{array}{l}\text { University } \\
\text { degree [n=1] } \\
\text { Upper } \\
\text { secondary } \\
\text { diploma [n = 2] }\end{array}$ \\
\hline & & Interpreter & $\begin{array}{l}\text { Upper } \\
\text { secondary } \\
\text { diploma }[n=1]\end{array}$ \\
\hline $\begin{array}{l}\text { Lecturer* } \\
\text { [n = 1] }\end{array}$ & $\begin{array}{l}\text { - Delivering the societal } \\
\text { information component }\end{array}$ & $\begin{array}{l}\text { Social Services: Department of } \\
\text { Family, Children and Youth }\end{array}$ & $\begin{array}{l}\text { University } \\
\text { degree }[n=1]\end{array}$ \\
\hline $\begin{array}{l}\text { Connect } \\
\text { instructors } \\
{[n=2]}\end{array}$ & $\begin{array}{l}\text { - Training the group leaders in the } \\
\text { Connect programme } \\
\text { - Supervising group leaders once } \\
\text { a week in the Connect } \\
\text { programme }\end{array}$ & $\begin{array}{l}\text { Social Services from another } \\
\text { municipality - external quality } \\
\text { assurance }\end{array}$ & $\begin{array}{l}\text { University } \\
\text { degree }[\mathrm{n}=2]\end{array}$ \\
\hline $\begin{array}{l}\text { Internal } \\
\text { facilitators } \\
{[n=2]}\end{array}$ & $\begin{array}{l}\text { - Sending text messages and } \\
\text { calling parents } \\
\text { - Babysitting } \\
\text { - Taking care of the welcoming } \\
\text { refreshments for the participants } \\
\text { - Arranging transportation }\end{array}$ & Social services & $\begin{array}{l}\text { Vocational } \\
\text { training diploma } \\
{[\mathrm{N}=2]}\end{array}$ \\
\hline $\begin{array}{l}\text { External } \\
\text { facilitator } \\
{[n=1]}\end{array}$ & $\begin{array}{l}\text { - Overall responsibility of the } \\
\text { implementation process } \\
\text { - Observing the societal } \\
\text { information sessions } \\
\text { - Quality assurance of the } \\
\text { intervention }\end{array}$ & University & $\begin{array}{l}\text { University } \\
\text { degree }[\mathrm{n}=1]\end{array}$ \\
\hline $\begin{array}{l}\text { *Two of the } \\
\text { group leade } \\
\text { intervention. }\end{array}$ & $\begin{array}{l}\text { up leaders also served as lecturer } \\
\text { so had the responsibility for recruit }\end{array}$ & $\begin{array}{l}\text { nd delivered the societal informa } \\
\text { g parents and facilitating the imp }\end{array}$ & $\begin{array}{l}\text { omponent. One } \\
\text { tation of the }\end{array}$ \\
\hline
\end{tabular}

The parents who participated in the parenting programme $(n=58)$ were between 30 and 70 years of age and had children aged 11 to 16 years. The majority (65\%) of the parents had lived in Sweden for $<5$ years. 


\section{Data Collection}

For this process evaluation study, both qualitative and quantitative data were collected and analysed [31]. Data were collected during the delivery of the four rounds of the programme and after its completion, as well as from focus group discussions [FGDs], a questionnaire, an attendance list, field and reflection notes, and observations of the societal information sessions. A semi-structured interview guide was used for the interviews. Six FGDs were conducted with group leaders, a lecturer, Connect instructors and internal facilitators.

To capture the fidelity of the parenting programme, the first author collected two participant observation notes from the societal information sessions, three reflection notes from those who delivered the societal information sessions and seven FGDs with Connect instructors, group leaders, a lecturer and internal facilitators. The observation and the reflection protocols were about overall impressions and interactions with the parents; the questions they most wanted to discuss; and session duration. Field notes were taken from the different sessions to examine the contextual factors of the implementation further.

In accordance with the Connect manual, instructors supervised group leaders after each session to ensure programme fidelity. Each session was video-recorded, and the recordings were sent to the Connect instructors. For this study, we did not analyse the video recording but held focus group interview with the instructors about their experiences training and supervising the group leaders, as well as the fidelity of the programme. The FGDs with the instructors were conducted in Swedish and lasted approximately 60 minutes.

The FGDs with the group leaders, lecturers and internal facilitators were about their experiences delivering the intervention, including their contact and interaction with participants, and contextual factors that affected the implementation. The FGDs lasted from 60 to 105 minutes. Five FGDs were conducted in Somali and one in Swedish.

To measure parents' satisfaction with the intervention, the Consumer Satisfaction Questionnaire (CSQ) was used [32]. The CSQ is a standardised instrument that was adapted for this study. It comprises 22 items addressing the impact of the parenting programme on the parents' knowledge, confidence parenting, and parent-child interactions and relationships. Parents were asked to rate each item on a scale from 1 (e.g., satisfaction with the programme or improvement of problems or parent-child relationships) to 4 (dissatisfaction with the programme or worsened problems or parent-child relationships). The 22 items were summarised to yield a total score between 22 and 88 , with low scores indicating higher satisfaction. The CSQ was administered to participants two months upon intervention completion.

Ethical approval for this study was obtained from the Swedish Regional Ethical Review Board in Uppsala, Sweden (Dnr 2014/048/1). 
Table 3

Data collection sources, participants and data analysis

\begin{tabular}{|c|c|c|c|}
\hline Data source & Participants/instruments & Data collection & $\begin{array}{l}\text { Data } \\
\text { analysis }\end{array}$ \\
\hline $\begin{array}{l}\text { FGDs with Connect } \\
\text { instructors, group leaders } \\
\text { and internal facilitators } \\
{[n=6]}\end{array}$ & $\begin{array}{l}\text { Group leaders who delivered the } \\
\text { intervention }[n=7] \\
\text { Internal facilitators who were } \\
\text { responsible for the practicalities [n } \\
\text { = 2] concerning the } \\
\text { implementation } \\
\text { Instructors of the Connect } \\
\text { programme }[n=2]\end{array}$ & $\begin{array}{l}\text { FGDs were conducted } \\
\text { after the four parent } \\
\text { groups were finished }\end{array}$ & $\begin{array}{l}\text { Inductive } \\
\text { qualitative } \\
\text { analysis }\end{array}$ \\
\hline Field notes & $\begin{array}{l}\text { Field notes of the external } \\
\text { facilitator during planning, delivery } \\
\text { and evaluation phases }\end{array}$ & $\begin{array}{l}\text { Field notes were made } \\
\text { during delivery of the } \\
\text { programme }\end{array}$ & $\begin{array}{l}\text { Deductive } \\
\text { qualitative } \\
\text { analysis }\end{array}$ \\
\hline Participant observation & $\begin{array}{l}\text { Participant observation of the } \\
\text { external facilitator on the societal } \\
\text { information sessions }[n=2]\end{array}$ & $\begin{array}{l}\text { Observations were } \\
\text { conducted during the } \\
\text { delivery of the } \\
\text { programme }\end{array}$ & $\begin{array}{l}\text { Deductive } \\
\text { qualitative } \\
\text { analysis }\end{array}$ \\
\hline Reflection & $\begin{array}{l}\text { Reflection notes from the two } \\
\text { group leaders and the lecturer }\end{array}$ & $\begin{array}{l}\text { Reflections were made } \\
\text { after the delivery of the } \\
\text { societal information } \\
\text { sessions }\end{array}$ & $\begin{array}{l}\text { Deductive } \\
\text { qualitative } \\
\text { analysis }\end{array}$ \\
\hline CSQ & $\begin{array}{l}\mathrm{CSQ} \text { is a standardised instrument } \\
\text { measuring parents' satisfaction } \\
\text { with the programme }\end{array}$ & $\begin{array}{l}\text { The questionnaire was } \\
\text { collected two months } \\
\text { after the programme } \\
\text { ended }\end{array}$ & $\begin{array}{l}\text { Descriptive } \\
\text { statistical } \\
\text { analysis }\end{array}$ \\
\hline Attendance list & $\begin{array}{l}\text { Attendance list collected from all } \\
\text { the sessions [ } n=12] \text { in the } \\
\text { programme }\end{array}$ & $\begin{array}{l}\text { The attendance list was } \\
\text { collected during the } \\
\text { delivery }\end{array}$ & $\begin{array}{l}\text { Descriptive } \\
\text { statistical } \\
\text { analysis }\end{array}$ \\
\hline
\end{tabular}

\section{Data analysis}

All FGDs were transcribed verbatim and analysed inductively with content analysis [33]. The transcribed FGDs with the Connect instructors were analysed separately. All transcribed data were read several times to capture the participants' overall experiences. Phrases, paragraphs and words that captured the key concepts were then highlighted and coded into initial codes. The next step involved sorting codes based on their similarities. These were then sorted according to the components of the process evaluation guidance.

The field notes, observations and reflection notes were analysed using deductive content analysis [33]. The analysis started with a reading of the text and then placing the text according to the components of the process evaluation guidance.

The CSQ was analysed in SPSS version 24 [34]. Descriptive statistics (frequencies and percentages) were calculated to describe the data. 
The overall findings showed that the programme was implemented and delivered as intended; however, the implementation strategy was adapted during the course of delivering the four rounds of the programme to meet the needs of the target group. Results are presented according to the Moore et al. [22] framework.

\section{Contextual Conditions For The Implementation}

Some group leaders lacked support from their manager, while group leaders who worked at schools reported that they did not have enough preparation time for the sessions. The group leaders suggested that the managers should be involved in the planning phase so that they could set aside time for group leaders to prepare and deliver the sessions. The group leaders estimated a need for 8-10 hours per week for preparation and delivery.

According to the internal facilitators, parents were unsure about the involvement of social services in their parenting and the delivery of the intervention. Therefore, it was important to start with the societal information sessions as one of the lecturers who later led the Connect programme stated:

It was crucial that we began by talking about social services work with children and youth. This gave parents an understanding of the true purpose of social services and also helped relieve them of some of their worries. It also facilitated the engagement of parents in other topics in the parenting programme. I think we should always start with what is important for parents or what concerns them.

According to the group leaders and the field notes, one factor that supported the implementation was the involvement at the programme start of key individuals who were well-known Somalis and respected within the community. These key individuals arranged and participated in the initial informal meetings and reassured parents about the benefits of participating in the parenting programme. The group leaders and external facilitators were also crucial in terms of the cultural competence that the programme required. One lecturer stated, "It was the right person behind each post/work that we are very grateful for".

The group leaders emphasised that programmes become sustainable when funded from the municipality or civil society. They believed that if the Somali associations [and not social services] had implemented the parenting programme, it might have been easier to recruit parents; on the other hand, this might have been difficult in terms of sustainability or quality assurance.

The internal facilitators stressed the fact that the venue was unsuitable for more than three children and lacked toys: this may have prevented couples from bringing their children and thereby being able to participate in the programme together. They suggested a more suitable and child-friendly venue where both young and older children can play during the sessions.

\section{Implementation Process}

Reach of the target group

Sixty parents were invited to participate in the programme. Of these, 58 did in fact participate, and nearly one third were fathers $(n=17)$. Of the 58,40 attended more than eight sessions while 17 attended fewer than eight 
sessions.

Adaptations to the implementation strategy and perceptions of the strategy

In addition to the components in the strategy to reach and retain parents, peer information [i.e. parents who completed the programme informing other presumptive participants about their experience] was added after the first two groups in the programme had completed their sessions. Peer information was felt to contribute to information about the programme reaching more parents.

Parents appreciated receiving a diploma upon successful completion of the programme, which was a strategy to retain their involvement.

An implementation strategy used in the programme was the sending of reminders to participants. However, it was soon realised that this strategy needed reinforcement and subsequently internal facilitators offered parents not living within the neighbourhood free transportation, which contributed to high attendance. One internal facilitator said:

In the beginning, when we saw that they [parents] hadn't arrived 30 minutes before the session, we phoned them. If they told us that they had difficulties coming due to a lack of transportation, we offered them a lift. However, we later came to give all parents who lived outside the neighbourhood a lift.

Many participants took advantage of the group leaders' and facilitators' willingness to read and write their letters at most of the sessions. One group leader described his experiences supporting participants: It was positive supporting parents with reading or writing letters for them because parents were stressed about all the letters they received. In addition, this kind of support was helpful to engage and retain the participants in the sessions.

Fidelity to the Ladnaan Programme and perceptions of delivering the intervention

The interviews with the group leaders showed that the training with other group leaders before and during the programme, along with the supervision, enhanced their competence and self-confidence in delivering the parenting programme.

Connect instructors reported that the group leaders were knowledgeable both during the Connect training course and during delivery of the sessions. According to the Connect instructors, group leaders delivered the programme according to the manual. The Connect instructors felt that the group leaders delivered the sessions sensibly, and that they listened to the parents and sought to explain information in different ways. They also encouraged group leaders to use metaphors and proverbs, as well as verses from religion, one Connect instructors explained:

I had encouraged them to use metaphors, proverbs and religious verses because we had noticed that parents became engaged in the topic and had a lot to discuss when the group leaders used a proverb, something from the Quran or sometimes their own experiences.

Connect instructors pointed out that the supervision sessions were very important to ensure that the programme was delivered as intended. The lectures on parenting style and the work of social services were held 
in one session and took longer than planned. As a result of the FGD with the group leaders and the lecturer's reflection notes, a suggestion was made to divide the two topics (societal information and parenting styles) into two sessions and to deliver the Parenting Styles lecture in Somali.

\section{Mechanism Of Impact}

The importance of parental engagement: the perspective of the group leaders

Group leaders reported that it took two to three sessions to build trust with parents and for parents to accept the programme. Some group leaders stated that most of the parents and group leaders knew each other and that this facilitated the building of trust with parents. Another crucial factor that contributed to the retention of participants was the Ladnaan Programme with its societal information component because most parents were eager to receive this information.

The group leaders agreed that the fact Somali was both their mother tongue and that of the parents served to increase parental involvement, which in turn contributed to their completing the programme. Further, the group leaders felt that the fact that they and the parents shared the same cultural background was a contributing factor for success. As one group leader stated:

I would say that the biggest success factor was that the group leaders and the parents shared the same country, culture and language and understood each other... for instance, a Swedish group leader would present the message and I would add examples from the culture or examples that they could identify with. (Female group leader 3)

The use of poetry, proverbs and metaphors served to make the programme culturally sensitive; this seemed to help the parents understand, recognise and realise the universality of parenting. Group leaders noted that the adaptation of role-play exercises and examples was crucial for parents to understand and view parental-child interaction from different perspectives, which led to further reflections and discussions on the part of the parents.

Parent satisfaction with the Ladnaan Programme

Parents were asked about their satisfaction with the Ladnaan Programme. The CSQ showed that 96\% [ $\mathrm{n}=55$ ] of participants were very satisfied. Most (70\%) reported increased knowledge about social services and increased confidence to seek support from social services when facing difficulties with their children. All participants $(n=57)$ stated that their relationships with their children had improved. They reported a better postprogramme understanding of themselves as parents, and of their children's needs and behaviour; they also reported feeling more secure in their parenting role in Sweden. The total satisfaction $(n=39)$ ranged from 24 to $43(M=26.38, S D=4.13)$. Overall, these findings demonstrate families' high satisfaction with the programme.

\section{Discussion}

This process evaluation highlights several key aspects that need to be considered when implementing parenting programmes to immigrant parents through social services. In the following section, the key aspects

Page $12 / 18$ 
related to contextual factors, the implementation process and the mechanism of impact are discussed. The key aspects related to contextual factors facilitated trust-building with the Somali-born parents and their engagement in the programme. The programme implementation and impact were facilitated by way of the facilitators' and group leaders' cultural awareness and sensitivity. Such a process evaluation suggests the importance of reaching and retaining when implementing parenting programmes to immigrant parents.

\section{Trust-building}

According to Moore et al. [22], contextual factors that may facilitate or impede the implementation of a parenting programme must be considered. This study has identified several contextual factors. One such factor that enabled engagement, recruitment and retention of Somali-born parents was early-phase involvement of key individuals as this helped build trust within the Somali community. Crucial to the engagement of parents in the programme were their understanding of its benefits to both them and their children, and the face-to-face provision of information at meetings. This is in line with a systematic review [19] showing that the involvement of key individuals who are trusted and known by the target group is critical when recruiting immigrant parents into parenting programmes and their consequent engagement. Our study also noted that parents from the first two groups informed other parents.

A contextual factor for the specific target group was that Somali-born parents who were new in Sweden were unfamiliar with the function of authorities and were afraid of the legal authority that, for example, social services had to apprehend their children $[6,12,13]$. Our findings indicate the benefits that came with having social services deliver the parenting programme as this led to less fear and increased confidence when it came to parents seeking support from them. Having social services deliver the intervention can contribute to quality assurance and sustainability of support services to parents who are the most vulnerable. A contextual factor that needs to be considered in terms of sustainability and quality assurance is to involve group leaders within the municipality because this will ensure sustainability and trust-building with the community. Another contextual factor is ensuring that group leaders receive time for preparation. In this study, some group leaders prepared for the sessions in their spare time.

\section{Cultural Awareness}

Adaptation of interventions to different contexts may ensure greater acceptance of the programme among participants $[19,38]$. However, the adaptation must consider contextual as well as cultural aspects while maintaining the core components of the interventions. In this study, the programme was delivered in the parents' native language by Somali group leaders who had similar backgrounds to the parents. Group leaders in this study highlighted the importance of delivering parenting programmes in the parents' native language and of having group leaders with contextual and cultural competence. Several studies underscore the importance of cultural sensitivity in the interventions $[18,19,35,37]$; that parenting programmes delivered in the native language and tailored to their parents' needs are more effective [18, 19]. In this study, group leaders drew upon their own experiences and used Somali metaphors and proverbs to emphasise certain elements of the programme: this facilitated not only understanding but also a sense of familiarity and equality. 
Retention of parents in the programme was improved as a result of the cultural awareness of facilitators and group leaders. Previous studies $[18,19,39]$ report on the practical issues that may hinder parents from participating in the parenting programme, such as transportation, childcare, scheduled times and other stressful factors. Parents in our study were offered childcare services during the sessions but few used it. The study demonstrated the importance of offering childcare in a child-friendly venue with age-related activities for children. The phone reminders, assistance reading government correspondence, and transport to the sessions were reported to reduce parental stress.

\section{Limitations Of The Study}

Data collection was carried out by the first author (FO), who was also involved in the development of the programme. The analysis and interpretation of the study, meanwhile, were carried out by the entire research group, who continuously discussed data analysis and interpretation of results. In this study, parents were not interviewed about their views on strategies to recruit and to reach them, which we feel to be a limitation. The contextual factors of this implementation process relate to only one municipality; however, they are in line with previous international research $[18,19,39]$. Nevertheless, this is a limitation of this study, and as such, studies need to be made of the delivery of this type of programme in major cities and with other groups.

\section{Conclusion}

This study provides knowledge about a well-described strategy for the implementation of a parenting programme, and guidance on how to reach and retain immigrant parents to parenting programmes. We found that contextual factors, such as matching the group leaders and the parents (shared language), and cultural awareness, are important when it comes to building trust with immigrant parents and engaging them in parenting programmes. In the implementation of evidence-based practice in the delivery of social services, it is important to consider both the specific group for which the intervention is intended as well as any prevailing contextual factors. The fact social services delivered the parenting programme led to confidence among Somali-born parents when it came to their seeking support from social services. In terms of the implementation of beneficial evidence-based programmes, it is crucial that policymakers have information on how to deliver a programme and how to reach target groups so that this can be transferred to other settings.

\section{Abbreviations}

CSQ Consumer Satisfaction Questionnaire

CRC Convention on the Rights of the Child

FGD Focus group discussion

\section{Declarations}

Ethics approval and consent to participate 
This study has received ethical approval from the Regional Ethical Review Board in Uppsala, Sweden (Dnr 2014/048/1). Participants have received an information letter before participating and gave written consent (inperson interview) and verbal consent (phone interview) to participate. At any time during data collection, participants were allowed to decline from answering any questions or withdraw from the study without consequence.

\section{Consent for publication}

All participants gave written consent to publish the research findings.

\section{Availability of data and materials}

Data will not be shared as ethics approval does not permit the sharing of data because of issues of confidentiality.

\section{Competing interests}

The authors declare that they have no competing interests.

\section{Funding}

This work was funded by the Public Health Agency of Sweden (grant number: 802/2014-6.2).

\section{Authors' contribution}

All authors: F.O., U-K.S., M.K.A. and R.F. were responsible for the study design. F.O. collected the data and was responsible for the data analysis and the writing of the manuscript. FO, MT and U-K.S were responsible for the analysis. All authors took part in analysing, reviewing the manuscript and critically revised, read and approved the final manuscript.

\section{Acknowledgements}

The authors would like to thank all participants who took time out of their busy schedules to be part of this study. We also thank the Public Health Agency of Sweden for funding this study.

\section{References}

1. Eurostat. Migration and migrant population statistics 2019. January Eurostat. Migration and migrant population statistics 2019. January. Eurostat. https://ec.europa.eu/eurostat/statistics-

explained/index.php/Migration_and_migrant_population_statistics\#Migrant_population:_22.3_million_nonEU_citizens_living_in_the_EU_on_1_January_2018.

2. Lindencrona F, Ekblad S, Hauff E. Mental health of recently resettled refugees from the Middle East in Sweden: the impact of pre-resettlement trauma, resettlement stress and capacity to handle stress. Soc Psychiatry Psychiatr Epidemiol. 2008;43:121-31.

3. Chen W, Ling L, Renzaho AM. Building a new life in Australia: an analysis of the first wave of the longitudinal study of humanitarian migrants in Australia to assess the association between social 
integration and self-rated health. BMJ Open. 2017;7:e014313.

4. Warfa N, Curtis S, Watters C, Carswell K, Ingleby D, Bhui K. Migration experiences, employment status and psychological distress among Somali immigrants: a mixed-method international study. BMC Public Health. 2012;12:1-12.

5. Betancourt TS, Abdi S, Ito BS, Lilienthal GM, Agalab N, Ellis H. We Left One War and Came to Another: Resource Loss, Acculturative Stress, and Caregiver-Child Relationships in Somali Refugee Families. Cultur Divers Ethnic Minor Psychol 2014.

6. Nilsson JE, Barazanji DM, Heintzelman A, Siddiqi M, Shilla Y. Somali Women's Reflections on the Adjustment of Their Children in the United States. J Multicult Couns Dev. 2012;40:240-52.

7. Renzaho AMN, McCabe M, Sainsbury WJ. Parenting, role reversals and the preservation of cultural values among Arabic speaking migrant families in Melbourne, Australia. Int J Intercult Relat. 2011;35:416-24.

8. Deng SA, Marlowe JM. Refugee Resettlement and Parenting in a Different Context. J Immigrant Refug Stud. 2013;11:416-30.

9. Lewig K, Arney F, Salveron M. Challenges to parenting in a new culture: Implications for child and family welfare. Eval Program Plann. 2010;33:324-32.

10. Renzaho AMN, Green J, Mellor D, Swinburn B. Parenting, family functioning and lifestyle in a new culture: the case of African migrants in Melbourne, Victoria, Australia. Child Fam Soc Work. 2011;16:228-40.

11. Degni F, Pöntinen S, Mölsä M. Somali Parents' Experiences of Bringing up Children in Finland: Exploring Social-Cultural Change within Migrant Households. Forum: Qual Soc Research Social Work Pract. 2006;7:3.

12. Heger Boyle E, Ali A. Culture. Structure, and the Refugee Experience in Somali Immigrant Family Transformation. Int Migr. 2010;48:47-79.

13. Osman F, Klingberg-Allvin M, Flacking R, Schön U-K. Parenthood in transition - Somali-born parents' experiences of and needs for parenting support programmes. BMC Int Health Hum Rights. 2016;16:1-11.

14. Bowie BH, Wojnar D, Isaak A. Somali Families' Experiences of Parenting in the United States. West J Nurs Res. 2017;39:273-89.

15. Osman F, Flacking R, Schön U-K, Klingberg-Allvin M. A Support Program for Somali-born Parents on Children's Behavioral Problems. Pediatrics. 2017;139:3.

16. Osman F, Salari R, Klingberg-Allvin M, Schön U-K, Flacking R. Effects of a culturally tailored parenting support programme in Somali-born parents' mental health and sense of competence in parenting: a randomised controlled trial. BMJ Open. 2017;7:12.

17. Baker CN, Arnold DH, Meagher S. Enrollment and Attendance in a Parent Training Prevention Program for Conduct Problems. Prev Sci. 2011;12:126-38.

18. Griner D, Smith TB. Culturally adapted mental health interventions: A meta-analytic review. Psychotherapy. 2006;43:531-48.

19. Mytton J, Ingram J, Manns S, Thomas J. Facilitators and Barriers to Engagement in Parenting Programs. Health Educ Beha. 2014;41:127-37.

20. Koerting J, Smith E, Knowles MM, Latter S, Elsey H, McCann DC, et al. Barriers to, and facilitators of, parenting programmes for childhood behaviour problems: a qualitative synthesis of studies of parents' and professionals' perceptions. Eur Child Adolesc Psych. 2013;22:653-70. 
21. Rabin BA, Brownson RC. Terminology for Dissemination and Implementation Research. In: Brownson RC, Colditz GA, Proctor E, editors. Dissemination and Implementation Research in Health. New York: Oxford University Press; 2018. pp. 19-45. [Eds].

22. Moore GF, Audrey S, Barker M, Bond L, Bonell C, Hardeman W,.. . Baird J. Process evaluation of complex interventions: Medical Research Council guidance. BMJ 2015; 350:350, h1258.

23. Proctor E, Silmere H, Raghavan R, Hovmand P, Aarons G, Bunger A,.. . Hensley M. Outcomes for implementation research: conceptual distinctions, measurement challenges, and research agenda. Adm Policy Ment Health. 2011;38(2):65-76.

24. Slaughter SE, Hill JN, Snelgrove-Clarke E. What is the extent and quality of documentation and reporting of fidelity to implementation strategies: A scoping review. Implement Sci. 2015;10:129.

25. Proctor EK, Powell BJ, McMillen JC. Implementation strategies: recommendations for specifying and reporting. Implement Sci. 2013;8:139.

26. Osman F, Flacking R, Klingberg Allvin M, Schön U-K. Qualitative study showed that a culturally tailored parenting programme improved the confidence and skills of Somali immigrants. Acta Paediatr. 2019;108:1482-90.

27. Statistics SCB. Befolkning efter födelseland, ålder och kön. 2019. http://www.statistikdatabasen.scb.se/.

28. Osman F. Ladnaan: evaluation of a culturally tailored parenting support program to Somali-born parents. Stockholm: Karolinska institutet; 2017.

29. Moretti MM, Obsuth I, Craig SG, Bartolo T. An attachment-based intervention for parents of adolescents at risk: mechanisms of change. Attach Hum Dev. 2015;1:119-35.

30. Moretti MM, Braber K, Obsuth I. Connect. An Attachment-focused treatment group for parents and caregivers-A principle based manual. British Columbia: Simon Fraser University.: Burnaby; 2009.

31. Creswell JW. Research design: Qualitative, quantitative, and mixed methods approaches. California: Sage publications; 2013.

32. Eyberg S. Consumer satisfaction measures for assessing parent training programs. Innovations in clinical practice: A source book, 1993; 12: 377-382.

33. Elo S, Kyngas H. The qualitative content analysis process. J Adv Nurs. 2008;62:107-15.

34. IBM. IBM SPSS Statistics for Windows, Version 24. Armonk: IBM Corp; 2016.

35. Birman D, Beehler S, Harris EM, Frazier S, Atkins M, Blanton S,.. . Liautaud J. International Family, Adult, and Child Enhancement Services (FACES): A community-based comprehensive services model for refugee children in resettlement. Am J Orthopsychiat. 2008;78:121-32.

36. Goździak EM. Training refugee mental health providers: Ethnography as a bridge to multicultural practice. Hum Organ 2004;203-210.

37. Murray KE, Davidson GR, Schweitzer RD. Review of refugee mental health interventions following resettlement: best practices and recommendations. Am J Orthopsychiat. 2010;80:576-85.

38. Sundell K, Beelmann A, Hasson H, von T Schwarz. U. Novel Programs, International Adoptions, or Contextual Adaptations? Meta-Analytical Results From German and Swedish Intervention Research. J Clin Child Adolesc Psychol. 2016;45:784-96. 
39. Goodkind JR. Effectiveness of a community-based advocacy and learning program for hmong refugees. Am J Community Psychol. 2005;36:387-408.

\section{Figures}

\section{Ladnaan programme}

\section{Societal Information}

1. Child Welfare Services

2. Parenting Styles

3. United Nation's Convention on the Rights of the Child

\section{Connect parenting} programme

1. Introduction attachment theory

2. All behaviour has a meaning

3. Attachment is for life

4. Conflict is a part of attachment

5. Autonomy includes connection

6. Empathy

7. Balance our needs and the needs of others

8. Growth and change

9. Celebrating attachment

10. Two steps forward, one step back

Figure 1

Components of the Ladnaan Programme 